\title{
Dilemas da gestão democrática da educação frente ao contexto da Nova Gestão Pública
}

\author{
Dilemmas of democratic management of education outside the context of New \\ Public Management \\ Los dilemas de la gestión democrática de la educación frente al contexto de la \\ Nueva Gestión Pública \\ LUZENIR POLI
ROSILENE LAGARES
}

Resumo: A gestão democrática é processo; enfrenta tensões entre o experenciado historicamente, concepções coexistentes e em disputa. No contexto da chamada Nova Gestão Pública, práticas contraditórias são difundidas e, ante o esforço de transformação e/ou construção de outra realidade e dilemas dele advindos, há estagnações, retrocessos e avanços. A partir dessa tese, objetiva-se neste ensaio discutir aspectos que têm favorecido ou dificultado a democracia. Evidenciamse, nos conflitos de enfrentamento de dilemas, riscos de retrocessos autocráticos e necessidade de análise e esforço para a estes se contrapor.

Palavras-chave: Democracia. Política Pública Educacional. Gestão da Educação.

Abstract: The Democratic administration is proceeding; faces tensions between the experienced historically, coexisting conceptions and in dispute. In the context of the so-called New Public Management Practices contradictory are disseminated and, compared to the effort of processing and/or construction of another reality and his dilemmas arising, there estagnações, setbacks and advances. From this thesis, this essay aims to discuss aspects that have helped or hindered democracy. It is evident, in the conflict of facing dilemmas, risks of setbacks and autocratic need to analysis and effort to align them.

Keywords: democracy. Public Policy Education. Management of Education.

Resumen: La gestión democrática es un proceso; Se enfrenta a tensiones entre lo experimentado históricamente, concepciones coexistentes y en disputa. En el contexto de la llamada Nueva Gestión Pública, las prácticas contradictorias son difundidas y, ante el esfuerzo de transformación y / o construcción de otra realidad y dilemas de él venidos, hay estancamientos, retrocesos y avances. A partir de esa tesis, en este ensayo se objetiva discutir aspectos que han favorecido o dificultado la democracia. Se evidencia, en los conflictos de enfrentamiento de dilemas, riesgos de retrocesos autocráticos y necesidad de análisis y esfuerzo para contrarrestarlos.

Palabras clave: Democracia. Las políticas públicas de educación. La gestión de la educación. 


\section{INTRODUÇÃO}

A gestão democrática da educação pública como princípio constitucional (BRASIL, 1988, art. 206) é uma conquista que advém de lutas históricas. O termo tem sido disputado por diferentes concepções. Debates são suscitados em diversos âmbitos, dados os diversos entendimentos a seu respeito.

Com o avanço global do capitalismo, a chamada Nova Gestão Pública adentra a política pública educacional brasileira nos anos 1990, no contexto das reformas neoliberais (OLIVEIRA, 2015), ressignifica termos como gestão democrática, participação e descentralização, promovendo uma série de contradições e dilemas.

Neste ensaio, apresentamos uma discussão que tem a gestão democrática no campo da educação como objeto, entendendo-a como processo que enfrenta oposições tensionantes entre o experenciado historicamente, concepções coexistentes e a disputa na construção de outra realidade. Ante o esforço dessa construção e dilemas dele oriundos, há inalterações, retrocessos e avanços.

A partir desse pressuposto, o objetivo é abordar aspectos que têm favorecido ou dificultado a democracia. Faz-se, para esse fim, uma abordagem de conjunturas, à luz de teóricos como Gramsci (1978), Coutinho (1979), Saviani (1981), Bordenave (1985), Bobbio (1986), Wood (2003; 2007), Chauí (2004), Azevedo (2011), Lima (2013).

Para uma exposição lógica, o texto está organizado em três seções: na primeira, levantamos, a partir do contexto atual, questões que instigam à pesquisa do tema; na segunda, abordamos a construção da gestão democrática como princípio constitucional e na terceira seção, discutimos dilemas produzidos no contexto do capitalismo e da Nova Gestão Pública, para que se vivencie o processo democrático, evidenciando-se o conflito para exercitar a democracia e dar conta das demandas emergenciais, assim como ter participação ativa nas decisões, sendo, ao mesmo tempo, coerente com a transformação/emancipação sócio-política. Ainda, apresentamos algumas considerações finais, entendendo que há muito a ser pesquisado e discutido a fim de se descortinarem textos e contextos relativos ao tema. 


\section{GESTÃO DEMOCRÁTICA COMO PRINCÍPIO CONSTITUCIONAL}

Carlos Drumond de Andrade, em seu célebre poema "Nosso tempo"1, escreveu: "As leis não bastam. Os lírios não nascem da lei". De fato, estar normatizado não é suficiente; é preciso que a normatização seja uma construção social e que seja efetivada.

Nesse sentido, consideramos importante resgatar que a gestão democrática como princípio constitucional da educação pública surge a partir de lutas históricas. Embora na década de 1930 (AZEVEDO, 2010), o Manifesto dos Pioneiros da Educação tenha apontado a necessidade de democratização da educação - a despeito de se fazerem presentes no documento concepções outras acerca desse conceito - esse conteúdo não foi tratado na Constituição de 1934 (BRASIL, 1934), que inaugura, na legislação, a necessidade de "traçar as diretrizes da Educação Nacional" (Art. $5^{\circ}$, inciso XIV).

Os ideais progressistas de educação são reassumidos na Constituição de 1946, na atribuição da discussão em torno das "diretrizes e bases da educação nacional" a uma comissão constituída por educadores de diversas tendências (SAVIANI, 2002). Entretanto, é após a reorganização partidária iniciada no final da década de 1970, que a gestão democrática vem a tornar-se princípio legal da educação pública, na Constituição Federal de 1988 (BRASIL, 1988), art. 215, inciso VI.

Posteriormente, na Lei no 9.394/96, de Diretrizes e Bases da Educação Nacional - LDBEN (BRASIL, 1996) - em seu art. $3^{\circ}$, inciso VII, ressoa o princípio constitucional da gestão democrática do ensino público, estabelecendo que esta deva ocorrer na forma da LDBEN e "da legislação dos sistemas de ensino". No art. 14, incisos I e II, fica disposto que as normas de gestão democrática dos sistemas de ensino deverão assegurar como princípios: a "participação dos profissionais da educação na elaboração do projeto pedagógico da escola" e "das comunidades escolar e local em conselhos escolares ou equivalentes” (Idem - grifos nossos).

Cury (2002) sinaliza que a reflexão acerca dessa participação deve dar-se a partir do caráter da nossa Constituição (BRASIL, 1988): "Todo poder emana do povo, que o exerce por meio de representantes eleitos ou diretamente"

\footnotetext{
1 Poema de Carlos Drummond de Andrade escrito duas décadas antes do golpe militar de 1964, no contexto da Segunda Guerra Mundial.
} 
(art. $1^{\circ}, \int$ único). Desse modo, explicita que a democracia representativa não é suficiente; precisa de aperfeiçoamento com mecanismos de participação direta, com ampliação da cidadania.

Seguindo o ordenamento jurídico, o Plano Nacional de Educação (PNE) 2001-2011, aprovado por intermédio da Lei no 10.172/2001 (BRASIL, 2001), além de reafirmar o conteúdo constitucional, apresenta, dentre os princípios de formação dos professores e valorização do magistério, a vivência de formas de gestão democrática. No eixo de Financiamento e Gestão, define que cada sistema deveria implantá-la na forma de Conselhos de Educação, no âmbito do sistema; na forma de conselhos escolares com representação da comunidade educacional, no âmbito das escolas. A escolha de diretores é enunciada mediante garantia de competência e compromisso com a proposta definida pelos conselhos escolares. É também insistente a necessidade de controle social dos recursos por meio dos Conselhos de Educação. No documento, observa-se conteúdo bem voltado à necessidade de normatização da gestão democrática, às formas representativas de participação e ao controle dos recursos financeiros.

Com a aprovação do novo PNE (2014-2024), a gestão democrática ganha ênfase. A Lei no 13.005/2014 (BRASIL, 2014) a apresenta como princípio (art. $2^{\circ}, \mathrm{VI}$ ) e como método de construção dos planos decenais de educação (art. $8^{\circ}$, $\int 2^{\circ}$ ) e define prazo de dois anos para que os entes federativos aprovem suas leis regulamentando-a. Além disso, o PNE traz uma meta (Meta 19) e oito estratégias especificamente relacionadas à gestão democrática, referentes à: constituição, formação e manutenção de colegiados (conselhos, fóruns, grêmios); participação das famílias e dos profissionais da educação; controle social e fiscalização dos recursos públicos e escolha de diretores, mediante mérito, desempenho e consulta pública.

Das leis à efetividade, um enorme hiato, pois, se foi por meio de lutas históricas que a gestão democrática chegou às normas, as disputas provenientes desse processo perpassam a continuidade progressiva dessa trajetória.

\section{EDUCAÇÃO E GESTÃO DEMOCRÁTICA}

Parafraseando Azevedo (2011) perguntamos “O que há de novo em tão antigo tema?" (p. 411).

A afirmação de que a reflexão e a transformação/emancipação políticosocial estão no foco da educação que buscamos aparece, por vezes, em discursos docentes e documentos. Afinal, não tem sido esse o desafio que se coloca aos profissionais da educação e, mais especificamente, aos professores?! No entanto, em uma realidade bastante comum na educação brasileira, essa luta se trava em 
meio a "heranças" que ainda não conseguimos superar. Dentre elas, a fragmentação do tempo e a definição de conteúdos previstos como parte das "expectativas de aprendizagem”, em organização curricular que, mantendo algumas características cartesianas, ora avança timidamente ora retrocede. Embora alguns trabalhem buscando um viés participativo, reflexivo e transformador, os traços do paradigma racional tecnológico aparecem na definição tempo/espaço, conteúdo, sistema de avaliação e outros. O rompimento com esse paradigma é dificultado pela dinâmica da educação, que, no afã de dar respostas rápidas às pressões por resultados, cai no ativismo. Contreras (2002) sinaliza que os professores tendem a circunscrever sua ação e reflexão ao contexto da aula e à conjuntura mais imediata; por isso, acabam submetendo-se às rotinas.

Essa questão não diz respeito unicamente ao professor, mas a uma realidade guiada pela 'fluidez' mercadológica, pela competitividade. Refletindo sobre isso, podemos pensar em 'tendência' como inclinação/disposição natural ou como aquilo que leva alguém a agir de certo modo ${ }^{2}$. Ser levado pode significar alienação; daí, surge a necessidade de reflexão à luz das teorias, a fim de se lidar com múltiplas determinações internas e externas; as primeiras, advindas da formação introjetada, da absorção de ideologias dominantes, e as demais, advindas de imposições regulatórias.

A construção histórica de nossa realidade nos coloca, pelo menos, em situação de conformação ou de enfrentamento ou, ainda, de resistência, considerando-se o limiar entre as defesas discursivas e nossas condições reais de existência frente ao sistema econômico, onde tudo se torna capital. Nesse sentido, Gramsci (1978) evidencia a relação de algumas condutas com a eficácia política das ideologias. Há de se fazer, portanto, um esforço dialético para romper com os paradigmas excludentes que naturalizam, reforçam e ampliam as injustiças e as desigualdades sociais. O percurso dialético é, então e sobretudo, democrático, pois não há antítese sem escuta, sem observação, sem consideração ao outro.

A experiência com a organização e a própria participação como membros de conselhos e fóruns de educação nos permitiu observar que a mobilização para comparecimento às reuniões e participação, de forma efetiva, nas discussões enfrenta obstáculos e demanda bastante esforço. Contudo, quando há um mover, ainda que incipiente, esses mecanismos evidenciam a riqueza da democracia como processo e valor (COUTINHO, 1979). A exemplo, destacamos a observação de um episódio ocorrido na avaliação, mediante a elaboração e aplicação de questionário, da oferta da educação integral feita por representantes de um Conselho Municipal de Educação. Em plenária, os conselheiros profissionais da educação debatiam o www.dicio.com.br/tendencia/. Acesso em 16 dez. 2016, às 15h.) 
resultado das entrevistas, enquanto a representante de pais, mães e responsáveis senhora sem formação superior, que, com aparente timidez, ouvia o 'pedagogês' utilizado - depois de muito embate, levanta-se e, com sabedoria, interrompe, questionando: "Pessoal, eu não sou assim estudada como vocês e até pode ser que esteja errada, mas vocês não acham que a gente tinha de ouvir os alunos? Afinal, não é para eles que essa educação está sendo oferecida?!”.

Do exposto, também é possível questionarmos: Até que ponto a sociedade participa da definição e avaliação da política educacional? Que democracia está sendo vivenciada? Se a participação implica o envolvimento das pessoas na transformação da realidade político-social (BORDENAVE, 1985) e queremos transformação social, até onde avançamos, especialmente, quando se trata da educação? Estamos, de fato, dizendo ou estamos fazendo "eco"? Que concepções nos movem?

Bobbio (1986) destaca que a gestão democrática pressupõe a constituição de decisões coletivas e, por conseguinte, tem "prevista e facilitada" a ampla participação da sociedade. Essa participação exige esforço, tempo, espaço e construção das demais condições, pois a gestão democrática não é o caminho mais fácil, mais curto ou rápido, mas em nossa perspectiva é um processo formativo e de transformação/emancipação sócio-política. $\mathrm{Na}$ concepção crítica, ela é uma evolução dialética de aprendizado da cidadania ativa (WOOD, 2003) que requer proposição, debate e decisão coletivos em todas as dimensões e etapas; além disso, traz em seu escopo a descentralização do poder e o desenvolvimento da autonomia.

O desafio do desenvolvimento do processo democrático, ante as mazelas advindas do capitalismo, coloca-nos frente a dilemas que precisam ser discutidos e confrontados.

\section{DILEMAS NO CAMPO DA GESTÃO DEMOCRÁTICA}

O contexto da Nova Gestão Pública: "nem tudo que parece é"; nem tudo que é parece.

Segundo Oliveira (2015), em se tratando de sociedade capitalista, as relações sociais que acontecem em nível de Estado podem ser menos ou mais favoráveis a determinada classe, mas elas estarão sempre em defesa do capital.

Nessa perspectiva, é possível observar que, quando sobressaem medidas que vão na contramão dos desdobramentos da expansão mercadológica, uma das estratégias adotadas pelo neoliberalismo é a posse de termos constantes na pauta de reivindicação popular. Assim, discursos e planos com viés de exploração econômica simulam atendimento aos anseios daqueles que se encontram na base 
da pirâmide social e passam a ser aceitos ou incorporados. Contudo, diferente do que parece, esses termos são ressignificados tendo como objetivo fazer cumprir os interesses econômico-corporativos, que tendem a aumentar a desigualdade social e problemas dela provenientes.

É com essa perspectiva que, na década de 1990, a Nova Gestão Pública adentra a realidade brasileira no contexto de reformas reestruturantes que, sob pretexto de modernização do Estado, contribuíram para o "esmaecimento da noção de direito e da concepção de público que, nos anos de 1980, orientou o processo constituinte brasileiro" (OLIVEIRA, 2015, p. 630).

Com a Nova Gestão Pública, transpondo os critérios do mercado econômico privado para o campo da educação, o neoliberalismo orienta uma série de medidas justificadas, contraditoriamente, como forma de "atender às exigências dos movimentos sociais por maior participação" (Idem, p. 631). É sob a égide desse argumento que a descentralização e a participação tornam-se 'bandeiras'; a primeira toma contornos de desconcentração, com envolvimento apenas na implementação e execução; a segunda, como instrumento para referendar algo previamente determinado ou para decisão em torno dos processos de execução, dentro de limites já definidos. A sociedade civil é chamada à 'parceria' em que o envolvimento no nível individual e coletivo é buscado com o objetivo de criar soluções para problemas estruturais e de ordem geral. Nessa perspectiva, 'participação-parceira' significa, quase sempre, diminuição de custos e, logo, progressiva ausência do Estado.

Nesse contexto, termos como regulação e governança ganham força e a avaliação é destacada no âmbito das políticas públicas com diversos sistemas de avaliação e testes, cujos índices são perseguidos e, por vezes, utilizados como parâmetro na distribuição de recursos e na adoção de medidas meritocráticas (abonos, décimo-quarto salário e outros).

Destacamos que Oliveira (2015), citando Delvaux (2007), esclarece que o termo governance surgiu nas últimas décadas do século $\mathrm{XX}$, como resposta a uma demanda de estruturas de poder e governo infra e supra estatais, uma forma de limitar "a perda de eficácia nos processos decisórios que são cada vez mais especializados e compartimentados" (p. 633). Os principais difusores desse termo são o Banco Mundial e a Terceira Via.

No rol de medidas da Nova Gestão Pública, aparecem ainda as privatizações (na educação, sob forma de terceirizações), a adoção da gerência da qualidade total e da lógica da mensuração (tecnicista), a incorporação do empresariado aos debates educacionais. Com isso, mesmo a discussão sobre o currículo nacional adquire ênfase em organizações desse meio: Movimento Todos pela Educação, Fundação Lemann, Instituto Unibanco e Instituto Ayrton Senna, 
entre outros. Não obstante, avaliação, desenvolvimento de projetos e programas parecem negócios, onde recursos públicos são disputados por institutos, ONG e empresas de consultoria (OLIVEIRA, 2015).

O que podemos ver é que a Nova Gestão Pública ganha espaço no Brasil em 1990, mas tem se potencializado, gerando enormes contradições. Nesse contexto, a busca pela efetivação da gestão democrática é recheada de dilemas, onde encontramos oposições e vislumbramos possibilidades. São forças conflitantes que coexistem e tensionam o processo democrático, como destacamos.

\section{Coletividade X Individualidade: "farinha pouca, men pirão primeiro"}

Considerando que a sobrevivência diante do sistema econômico perpassa a necessidade monetária e a manutenção do emprego trilha a 'competividade', como realizar um processo democrático e agir coletivamente quando temos o individualismo difundido, exaltado e incorporado nas práticas cotidianas? No receio de perder algo de cunho pessoal ou de determinado lobby, aparecem defesas nem sempre direcionadas ao objetivo de combater a desigualdade e promover justiça.

Essa transformação social exige que a reflexão e a ação individual (não individualista) sejam agregadas a um processo coletivo e dele sejam agregadoras. Lima (2013) argumenta que é nas mobilizações e nas lutas conjuntas que se exerce a gestão democrática e se promovem mudanças.

Entretanto, Wood (2007) destaca a incompatibilidade entre democracia e capitalismo, pois onde impera a ganância e a acumulação de bens monetários há hierarquização das relações e a convivência entre pares fica impossibilitada, por se tratar de uma sociedade estratificada conforme o poder econômico.

\section{Dinâmica Inclusionista $\times$ Tendências Segmentadoras e Marginalizantes: o poder do mercado}

Democraticamente, pensamos em processos que primem pela igualdade, aqui tratada na perspectiva da equidade, uma dinâmica de inclusão daqueles que, por vezes, deixaram de ter vez e voz. Contudo, o poder econômico traz tendências segmentadoras e de marginalização, que vão desde as condições para sobrevivência até o status quo advindo do capital acumulado pelo sujeito e/ou sua ascensão ao poder. A indicação desse tensionamento é feita consoante as afirmações de Lima

3 Segundo o Dicionário de Expressões, um ditado popular: "diz-se de quem age egoisticamente pegando logo para si quando a quantidade não é suficiente para todos”. (Disponível em http:// www.dicionariodeexpressoes.com.br/busca.do? expressao $=$ Farinha $\% 20$ pouca, $\% 20 \mathrm{meu}_{0} \% 20 \mathrm{pir} \% \mathrm{E} 3 \mathrm{o} \% 20$ primeiro. Acesso em 23 fev. 2016). 
(2013), teórico que também explicita que o indivíduo capitalista tem suas escolhas definidas pelo mercado. Assim, não é mais ser humano passando a ser capital humano.

Segundo Wood (2003), o capitalismo promoveu uma tendência à apatia, pois sufocou o sujeito enquanto ser social, diluindo a política e a cidadania. Os ideais democráticos foram deturpados porque a liberdade e a igualdade não coadunam com desigualdade social e a exploração econômica.

Para além das forças tensionantes e opositoras ao processo democrático, enfrentamos dilemas existentes entre fazer valer seus princípios e, ao mesmo tempo, intervir na realidade em condições adversas constitutivas de invólucro do sistema econômico e de alienação historicamente construídos.

\section{Proposição, Debate e Construção Coletiva X Atendimento às Demandas Emergenciais}

Um processo democrático legítimo (COUTINHO, 1979) é formativo; requer tempo para proposição, debate e construção coletiva. Isso não significa esgotar tudo até ficar perfeito, mas aproximarmo-nos, progressivamente e em sociedade, daquilo que nos leva ao objetivo de justiça e igualdade social. Contudo, existem demandas emergenciais que também precisam ser resolvidas. Caímos, então, na famosa ação de 'trocar a roda com o carro andando' e eis aí o dilema. Como fazer para que o processo democrático (o carro) não pare, retroceda ou se perca sendo atraído por percursos históricos autocráticos e, ainda, dar conta das demandas que surgem (trocar a roda) nesse caminho? Nesse sentido, por vezes o foco se mantém na roda e se perde a visão de aonde de fato queremos chegar. Ressaltamos, então, que não se perder, dentre outras coisas, implica a necessidade de discernir entre as demandas sociais e as demandas mercadológicas do interesse de uma minoria privilegiada cujo objetivo é a acumulação de mais capital.

Com base em Chauí (2004), a instalação da democracia produziu a retirada do poder dos aristocratas e, na medida em que isso foi acontecendo, a cidadania passou a ser exercida e fortalecida nas discussões e deliberações realizadas nos momentos coletivos das assembleias. Desse modo, a história nos mostra que, por vezes, a dificuldade de identificar as demandas realmente importantes para fazer valer os princípios democráticos não é algo desejável à estrutura de poder e exploração econômica. O ativismo é, então, uma arma contra a reflexão e o descortinamento das reais razões que movem profissionais, alunos e pais à produção célere e ao efeito reflexo (não reflexivo) de tão somente atender às demandas. Nesse sentido, questionar é preciso e, aí, não se trata apenas de fazê-lo em relação aos outros, mas também de realizar autoquestionamento. Que razões e finalidades estão nos movendo?! 
Entre os quesitos básicos de implementação da gestão democrática, estão, segundo Lima (2013), "gostar de participar, querer participar, ter conhecimento do objeto de participação, se reconhecer neste objeto e ter o poder de participação nas tomadas de decisão" (p. 31).

Nessa perspectiva, podemos observar que outro dilema presente na efetivação da gestão democrática, tanto na escola quanto na dimensão do sistema de educação, é o enfrentamento das dificuldades de participação, uma vez que é forte o movimento contrário à efetivação de condições para exercê-la.

Importa ressaltar que o capitalismo deturpou o sentido de gestão e de democracia, buscando conformá-los à centralidade do mercado. Na contemporaneidade, há oposição entre a perspectiva tradicional (neoliberal) e a perspectiva crítica de gestão, de democracia e, consequentemente, de participação. Para a primeira, participar se reduz a um processo tático por meio do qual as massas populares são organizadas na defesa de interesses econômico-corporativos (COUTINHO, 1979). A partir desse modelo, temos, no campo da educação, a concepção de gestão compartilhada na qual a participação é um instrumento de controle e de validação de decisões definidas previamente. A possibilidade de decisão existe apenas no campo da execução, conforme limites previamente estabelecidos.

Angus (2001) destaca princípios da gestão empresarial apresentados nesse modelo: ênfase na eficiência e eficácia, com foco na instrução quanto aos modos e procedimentos; desconcentração das ações; incentivo à competição entre escolas como forma de atração de alunos devido aos índices obtidos (quota de mercado) e/ou para ter mais financiamento; os gestores (líderes de visão) são aqueles que, por força moral, podem estabelecer uma ordem negociada e, por isso, assumem lugar estratégico para difusão dos ditames do poder central.

$\mathrm{Na}$ perspectiva crítica, em direção contrária a esse modelo, o sentido de gestão democrática e, por conseguinte, de participação é o de um processo formativo, de transformação sócio-política, uma evolução dialética de aprendizado da cidadania ativa (WOOD, 2003). Desse modo, exige que haja condições, mecanismos e espaços para que a sociedade discuta e delibere, com efetividade, implicando organização do trabalho cooperativo, que, ao invés de firmar-se na competitividade, promove o exercício do poder em relações de complementariedade e não de hierarquização.

Pelo contexto de dilemas, as condições de participação não serão dadas. Antes, devem ser construídas no processo de enfrentamento, repelindo discursos e atitudes imobilizadoras e conformistas. Nesse sentido, sobressaem 
duas premissas: i) aprende-se a participar, participando; ii) a participação ativa cinde espaços, rompe com condicionantes, luta por condições, agrega e organizase junto a outros, formando um coletivo.

Então, o dilema - sendo a oposição e a possibilidade constitutivas do dilema - é: se é preciso querer participar e decidir fazê-lo ainda que não gostemos do esforço tensionante que esse exercício produz, é a partir dele que o coletivo se fortalece e passa a 'poder' participar e decidir. Mais que mera paixão, é preciso intencionalidade, um mover consciente e, por isso, decisão é sine qua non ${ }^{4}$ do início do processo e, também, de sua efetividade. Para gostar de participar é preciso decidir fazê-lo e onde a participação é cerceada existe dificuldade para decidir; onde ideologias camuflam as reais intenções existe alienação e, consequentemente, a dificuldade de cindir espaços.

\section{À GUISA DE CONCLUSÃO}

Com a Nova Gestão Pública, vai-se perdendo a perspectiva da educação enquanto direito social, como bem público. Contudo, educação não é mercadoria; não é algo a ser pensado apenas por especialistas e técnicos, por uma pessoa ou por um grupo. Não se pode transpor princípios fabris às escolas, sobrecarregando e impedindo a reflexão. Não se trata de custo-benefício, mas de investimento e ganhos sociais.

Nesse sentido, destacamos que a gestão democrática na política pública é, sobretudo, formativa, pois, especificamente na educação, implica: mediação de conflitos; escuta de projetos opositores; esforço tensionante para formulação de antítese e síntese; possibilidade de lidar com escolhas equivocadas, ainda que coletivas, para aprender com os próprios erros. Significa, cotidianamente, fazer o enfrentamento dos dilemas advindos de um processo que se dá em meio a concepções e projetos societários diversos, sensibilizados para a ideia de que as chances sejam constitutivas dos próprios dilemas.

A curvatura da vara (SAVIANI, 1981) deveria ir à direção oposta para, enfim, chegar a seu eixo. Contudo, na luta pela eliminação de preconceitos, outros estão sendo gerados; na busca pela liberdade, exercita-se a falta de respeito; no lugar da gestão democrática, condutas de gestão laissez-faire. Sendo assim, equilibrar a vara implica pensar e discernir entre o que deve ser reformulado e aquilo que deve ser mantido; é, por vezes, 'nadar contra a corrente'. Desse modo, diante da possibilidade de desgastes pessoais e coletivos, existe uma busca por

\footnotetext{
$4 \quad$ Expressão que originada do termo legal em latim que pode ser traduzido como "sem a/o qual não pode ser". Disponível em: https://www.significadosbr.com.br/sine-qua-non . Acesso em 13 mar. 2017.
} 
soluções prontas e rápidas. O risco iminente é de que, novamente, curve-se a vara a sua posição anterior, considerando a 'onda' de retrocessos que perpassa o Brasil e outros países.

Como na história do menino que foi condicionado a desenhar flor vermelha de cabo verde (BUCKLEY, s.d.), temos observado a volta de práticas que se encontravam em processo de arrefecimento. Cabe-nos questionar a que horizonte esse caminho nos levará. É preciso que haja análise e esforço na efetivação de políticas públicas educacionais que primem por processos de gestão democrática; que não caiam nem no autoritarismo nem na libertinagem ou no laissez-faire.

\section{REFERÊNCIAS}

ANGUS, L. Participación Democrática o Gestión Eficiente del Centro: la situación social y política de la autonomia escolar. In: SMITH, John (ed.). La Autonomia Escolar: uma perspectiva critica. Tradução: MANZANO, Pablo. Ediciones Akal, S.A., 2001, p. 19-44

AZEVEDO, F. O manifesto dos pioneiros da educação nova. Coleção Educadores. Brasília, Ministério da Educação. Domínio Público, 2010. Disponível em http://www.dominiopublico.gov.br/download/texto/me4707.pdf. Acesso em 20 dez. 2016.

AZEVEDO, J. M. L. de. Notas sobre a análise da gestão da educação e da qualidade do ensino no contexto das políticas educativas. RBPAE - v. 27, n. 3, p. 361-588, set./dez. 2011.

BOBBIO, N. O futuro da democracia: em defesa das regras do jogo. Rio de Janeiro: Paz e Terra, 1986.

BORDENAVE, J. E. D. O que é participação? São Paulo: Brasiliense, 6. ed., 1985.

BRASIL. Lei $\mathbf{n}^{\mathbf{0}}$ 13.005, de 25 de junho de 2014. Aprova o Plano Nacional de Educação - PNE e dá outras providências. Brasília: Senado Federal, 2014.

Lei $\mathbf{n}^{\mathbf{0}}$ 10.172, de 9 de janeiro de 2001. Aprova o Plano Nacional de Educação - PNE e dá outras providências. Brasília: Senado Federal, 2001. 
- Congresso Nacional. Lei de Diretrizes e Bases da Educação

Nacional no 9.394, de 20 de dezembro. Brasília: Senado Federal, 1996.

- Assembleia Constituinte. Constituição da República Federativa do Brasil. Brasília: Senado Federal, 1988.

BRASIL. Constituição da República dos Estados Unidos do Brasil de 1934. Disponível em <http://www.planalto.gov.br/ccivil_03/constituicao/ constituicao34.htm>. Acesso em: jan 2017.

BUCKLEY, H. E. Os gostos e as cores, in: http://revistaensinosuperior.uol. com.br/textos.asp?codigo=11137. (reescrito por Sergio Simka, s.d.).

CHAUÍ, M. Convite à Filosofia. São Paulo: Àtica, 2004.

CONTRERAS, J. A autonomia de professores. São Paulo: Cortez, 2002.

COUTINHO, C. N. A Democracia como Valor Universal. SILVEIRA, E. Encontros com a Civilização Brasileira. Rio de Janeiro. Civilização Brasileira, 1979 , p. 33-47.

CURY, C. R. J. Gestão democrática da educação: exigências e desafios. Revista Brasileira de Política e Administração da Educação, São Bernardo do Campo, v. 18, n. 2, jul./dez. 2002.

DELVAUX, B. L'action publique, ou analyser la complexité. Revue de la littérature (partie 4). Knowledge and Policy in education and health sectors. Brussels, jun., 2007.

GRAMSCI, A. Americanismo e fordismo. In: Obras escolhidas. São Paulo: Martins Fontes, 1978, p. 311-339.

LIMA, A. B. de. Adeus à Gestão (Escolar) Democrática. Revista @rquivo Brasileiro de Educação. Belo Horizonte, v. 1, n. 1, p. 27-50, 2013.

OLIVEIRA, D. A. Nova Gestão Pública e Governos Democrático-Populares: contradições entre a busca da eficiência e a ampliação do direito à educação. Educação e Sociedade, Campinas, v. 36, nº 132, p. 625-646, jul.-set., 2015 
SAVIANI, D. Escola e democracia ou a teoria da curvatura da vara. ANDE, Ano $1, \mathrm{n}^{\circ} 1$ p. 22-33, 1981.

Da nova LDB ao novo plano nacional de educação: por uma outra política educacional. Campinas: Autores Associados, 4 ed., 2002.

SILVEIRA, L. P. C. da; LAGARES, R. Educação e Gestão Democrática: dilemas e chances. 38 ${ }^{a}$ Reunião Nacional da ANPED. Anais... São Luiz: Universidade Federal do Maranhão, 2017.

Política e Educação no Brasil: o papel do Congresso Nacional na legislação do ensino. 5. ed. rev. Campinas, SP: Autores Associados, 2002.

WOOD, E. M. Democracia contra capitalismo: a renovação do materialismo histórico. São Paulo: Boitempo, 2003.

Estado, Democracia e Globalização. In: AMADEO, J.; BORON, A.; GONZALEZ, S. (org.). A Teoria Marxista Hoje: problemas e perspectivas. Buenos Aires: CLACSO; São Paulo: Expressão Popular, 2007. p. 381-393.

LUZENIR POLI é Mestranda em Educação pela Universidade Federal do Tocantins (UFT), Espc. em Gestão da Educação Municipal pela (UFT/Pradime, 2015), profa. da rede pública municipal de educação de Palmas, membro do Grupo de Estudos, Pesquisas e Extensão em Políticas Curriculares e Educativas (NEPCE), no Subgrupo de Estudo, Pesquisa e Extensão em Educação Municipal na UFT (EpeEM). Integrante do Grupo de Pesquisa da Rede Mapa (Gestão democrática do Ensino Público: mapeamento das bases normativas e das condições políticoinstitucionais dos sistemas municipais de ensino) e do Observatório de Sistemas e Planos de Educação no Tocantins (ObsSPE). E-mail: luzenirpoli@yahoo.com. br

ROSILENE LAGARES é Doutora em Educação pela Universidade Federal de Goiás (UFG, 2007), profa. da Universidade Federal do Tocantins (UFT) e do Programa de Pós Graduação em Educação; Diretora da Associação Nacional de Políticas e Administração da Educação (ANPAE) no Tocantins, uma das líderes do Grupo de Estudos, Pesquisas e Extensão em Políticas Curriculares e Educativas (NEPCE) e do Grupo de Pesquisa História, Historiografia, Fontes de 
Pesquisa em Educação da UFT; coordenadora do Subgrupo de Estudo, Pesquisa e Extensão em Educação Municipal na UFT (EpeEM), do Projeto de Pesquisa da Rede Mapa (Gestão Democrática do Ensino Público: mapeamento das bases normativas e das condições político-institucionais dos sistemas municipais de ensino), no Tocantins; e do Observatório de Sistemas e Planos de Educação no Tocantins (ObsSPE). E-mail: roselagares@uft.edu.br

Recebido em agosto de 2017 Aprovado em outubro de 2017 